\title{
Study of Factor Associated with Post Stroke Depression in the Teaching Hospital of Fann (Dakar-Senegal)
}

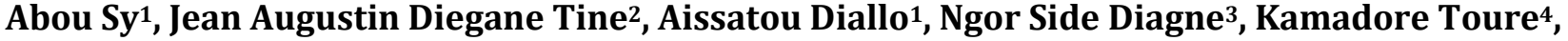 Ibrahima Seck ${ }^{2}$, Mamadouhabib Thiam ${ }^{1}$}

${ }^{1}$ Department Psychiatry, University Cheikh Anta DIOP, Dakar, Senegal

${ }^{2}$ Department Public Health, University Cheikh Anta DIOP, Dakar, Senegal

${ }^{3}$ Department Neurology, University Cheikh Anta DIOP, Dakar, Senegal

${ }^{4}$ Department Public Health, University of Thies, Thies, Senegal

Email: abousypsy@yahoo.fr

How to cite this paper: Sy, A., Tine, J.A.D., Diallo, A., Diagne, N.S., Toure, K., Seck, I. and Thiam, M. (2019) Study of Factor Associated with Post Stroke Depression in the Teaching Hospital of Fann (Dakar-Senegal). Health, 11, 1518-1528.

https://doi.org/10.4236/health.2019.1111114

Received: October 15, 2019

Accepted: November 12, 2019

Published: November 15, 2019

Copyright $\odot 2019$ by author(s) and Scientific Research Publishing Inc. This work is licensed under the Creative Commons Attribution International License (CC BY 4.0).

http://creativecommons.org/licenses/by/4.0/

\begin{abstract}
Introduction: Strokes are becoming more common in Africa, they are often accompanied by depressive symptoms, hence the need to investigate the factors associated with it for better management and prevention. Methodology: We conducted a prospective cross-sectional study amongst patients hospitalized with stroke at the Neurology/Neuroscience Clinic of the FANN UNHC (Dakar) in 2016. After a clinical diagnosis, patients are subjected to sociodemographic questionnaire and were administered with modified Rankin and MADRS scores. Results: Among the patients, 33.7\% had Post-Stroke Depression, most were aged 50 to 70 years, male and married. History of stroke and depression was strongly associated with Post-Stroke Depression, while functional or cognitive impairment caused by stroke contributed to the development of Post Stroke depression. The type of ischemic or haemorrhagic stroke did not appear to affect the occurrence of the Post-Stroke Depression, but Post-Stroke Depression was more frequent in subjects with a left hemispheric lesion 47.8\% ( $\mathrm{p}$ <.05). Discussion: The occurrence of a Post-Stroke Depression is a factor of poor prognosis, early diagnosis and holistic care lead to improved quality of life.
\end{abstract}

\section{Keywords}

Factor, Depression, Stroke, Dakar

\section{Introduction}

Strokes are becoming more common in our clinical practice in Sub Sahara Afri- 
ca [1] [2]. They often lead to physical and cognitive impairments and deficits, which are often accompanied by emotional disturbances and symptoms of depression [3]. Depression is a common and serious complication after stroke. According to epidemiological studies, nearly $30 \%$ of stroke patients develop depression, either in the early or in the late stages after stroke [4] [5].

Although depression may affect functional recovery and quality of life after stroke, such condition is often ignored [2]. In fact, only a minority of patients are diagnosed and even fewer are treated in the common clinical practice [6]. In particular, depression is considered as the strongest predictor of quality of life in stroke survivors, it is associated with an increased disability, increased cognitive impairment, increased mortality, both on short and long term, increase risk of falls and with worse rehabilitation outcome [2] [7]. So far, there has been no effective preventive intervention for post-stroke depression. We, however, found it necessary to study post-stroke depression to determine the patient profile and explore preventive strategy.

\section{Objectives}

The overall objective of our study was to determine the epidemiological profile of patients hospitalized for stroke at the Ibrahima Pierre Ndiaye Neurological/Neurosciences Clinic of National University Hospital Centre (CHNU) during the period from January 1, 2016 to December 31, 2016.

The specific objectives were to:

- Describe the socio-demographic characteristics of patients with Post-stroke depression hospitalized at the Neurological/Neurosciences I P Ndiaye Clinic of the CHNU de Fann during the period January 1, 2016 to December 31, 2016.

- Estimate the frequency of Post-stroke depression in patients hospitalized at the Neurological/Neurosciences I P Ndiaye Clinic of the CHNU de Fann during the period from January 1, 2016 to December 31, 2016.

- Estimate the frequency of motor deficits in patients hospitalized during the outflow of a stroke at the Neurological/Neurosciences I P Ndiaye Clinic of the CHNU de Fann during the period from January 1, 2016 to December 31, 2016.

\section{Material and Methods}

\subsection{Study Framework}

We conducted a study at the Neurology/Neurosciences Ibrahima PierreNdiaye Clinic of National University Hospital Centre (CHNU) of FANN in Dakar/Senegal. The CHNU de Fann is a level three public health institution.

\subsection{Type of Study}

It was a descriptive, prospective and quantitative study over a period of twelve (12) months from January 1, to December 31, 2016. 


\subsection{Population Study}

The study involved stroke patients during 2016 and admitted in the hospital at the Neurology/Neurosciences Ibrahima Pierre Ndiaye Clinic of National University Hospital Centre (CHNU) of FANN.

\subsection{Inclusion Criteria}

We included patients in our study the stroke victims confirmed by a brain scan in 2016 and hospitalized in the unit; who can be reached by telephone and/or able to travel (to return to the hospital), and be agreed to participate in the study.

\subsection{Exclusion Criteria}

We did not include patients with co-morbidities such as dementia or psychiatric disorders other than depression; with alertness disorders; undergoing neuroleptic treatments because of the probable psychomotor slowdown due to their sedative effect, and these who have been in the hospital for less than seven days.

\subsection{Data Collection}

We received all patients referred by the external consultation of the CHNU of Fann for hospitalization in the same department in which the stroke diagnosis is made. We subjected them to an investigator-administered questionnaire at admission during personal interview, and/or in the presence of their caregiver. The questionnaire explored socio-demographic, clinical and evolutionary information. Stroke was diagnosed using the clinical examination and brain scan results. Whereas, the diagnosis of depression was made according to the criteria of DSM V. The latter covers the different items of depression: mood, psycho-cognitive disorders, sleep and appetite disorders, psychomotor slowdown and somatic disorders.

The clinical evaluation was conducted using a variety of tools. Patients' functional status was assessed using the modified Rankin scale; it was used to measure the degree of disability or dependence in the daily activities of people who have had a stroke or other causes of motor neurological disability. In our study we considered any patient with a Rankin score higher than 3 (a judgment criterion very often used in neurovascular therapeutic studies) as having disability. The severity of depression was assessed using the MADRS scale, the scale is an investigator administered 10-item questionnaire used to assess the severity of depression in patients with mood disorders. The score not only confirms the diagnosis of depression but also determine its severity. The score can range from 0 to 60 . We selected patients that had a score above 20 ; this corresponds to moderate to severe depression.

\subsection{Data Entry and Analysis}

Data analysis was performed using Sphinx plus software version 5.1.05 and Epi 
info 7. We carried out a descriptive and bi-varied analysis, with dependent and independent variables. The results are expressed with a risk of error $\alpha$ equal 5\%.

\section{Results}

\subsection{Description of Patients}

The average age of our study population was $58.5( \pm 13.7)$ years. The median age was 60 years with extremes ranging from 30 to 84 years. In a study population of 98 stroke patients, 33 patients (33.67\%) were diagnosed with depression. Among patients who showed signs of depression on clinical examination, the MADRS found that severe depression was present at $3.03 \%$. The light depression was found in $63.64 \%$ of the patients (see Figure 1).

\subsection{Analysis of Depression by the Characteristic of Patients}

The prevalence of depression was 32.56\% among females and 34.55\% among males. Active patients were more likely depressed $39.22 \%$ than non-active patients $27.66 \%$. This difference was not statistically significant. In the same line, depression was more found in married patients $38.71 \%$ compared to single one. But this difference was not statistically significant.

Patients with history of stroke were depressed in $42.86 \%$. Depression was found in patients with diabetes in $22.22 \%$ compare to non-diabetes ones in $36.25 \%$. This difference was not statistically significant. The frequency of depression was $27.94 \%$ in hypertensive individuals and $46.67 \%$ in non-hypertensive individuals. This difference was not statistically significant. In the field of history of psychiatry disorders, we found $55.56 \%$ cases of depression.

According to our results, patients with aphasia were depressed in $42.86 \%$ and $21.43 \%$ in non-aphasic patients. This difference was statistically significant with a p-value equal to 0.02 . Patients with aphasia were 2.75 times more likely to be depressed IC $=[1.10-6.81]$. The prevalence of depression was $31.82 \%$ in subjects

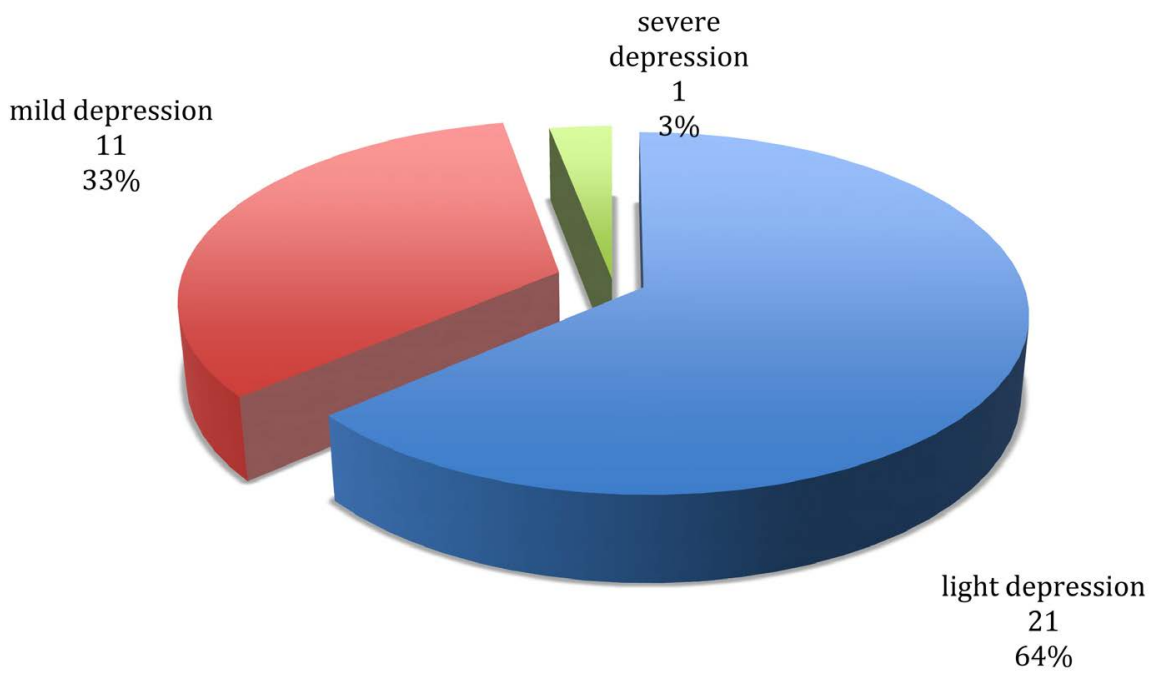

Figure 1. Distribution of patients according to the severity of depression $(\mathrm{N}=33)$. 
with haemorrhagic stroke and $34.21 \%$ in subjects with ischemic stroke. This difference was not statistically significant $(p=0.83)$. About the location, depression was found in $47.83 \%$ of patients with left hemispheric lesions and $22 \%$ in patients with right hemispheric lesions. This difference was statistically significant with p-value equal to 0.008 . Left hemispheric impairments were 3.25 times more likely to be depressed than right hemispheric impairments IC $=$ [1.34 - 7.87].

The accuracy of depression was $32.61 \%$ among individuals who had had functional rehabilitation and $40 \%$ among individuals who had not. This difference was not statistically significant.

The prevalence of depression was $75.76 \%$ in patients considered to have disability (Rankin $>3$ ) and $24.24 \%$ in autonomous patients (Rankin $\leq 3$ ). This difference was statistically significant ( $\mathrm{p}$-value $=0.04$ ). Patients with post-stroke disability were 2.56 times more likely to be depressed IC $=$ [1.34 - 7.87].

Among patients with depression $39 \%$ or 13 patients died, $36 \%$ lost eye sight (12 patients). A favourable evolution under treatment is reported in six patients, representing $18 \%$ of cases. While in two patients ( $7 \%$ of cases), we noted a persistence of depressive symptoms. Table 1 shows all the factors associated with depression among the patients with stroke.

Table 1. Associated factor of depression among stroke patient.

\begin{tabular}{|c|c|c|c|c|c|}
\hline \multirow{2}{*}{ Variables } & & \multicolumn{2}{|c|}{ Depression n (\%) } & \multirow{2}{*}{$\begin{array}{l}\text { TOTAL } \\
\mathrm{N}(\%)\end{array}$} & \multirow{2}{*}{$\mathrm{P}$} \\
\hline & & Yes & No & & \\
\hline \multirow{2}{*}{ Gender } & Female & $14(32.56)$ & $29(67.44)$ & $43(43.88)$ & \multirow{2}{*}{0.83} \\
\hline & Male & $19(34.55)$ & $36(65.45)$ & $55(56.12)$ & \\
\hline \multirow{2}{*}{ Employment } & Active & $20(39.22)$ & $31(60.78)$ & $51(52.04)$ & \multirow{2}{*}{0.25} \\
\hline & Non Active & $13(27.66)$ & $34(72.34)$ & $47(47.96)$ & \\
\hline \multirow{2}{*}{$\begin{array}{l}\text { Matrital } \\
\text { Statut }\end{array}$} & Married & $24(38.71)$ & $38(61.29)$ & $62(63.27)$ & \multirow{2}{*}{0.16} \\
\hline & Non married & $9(25.00)$ & $27(75.00)$ & $36(36.73)$ & \\
\hline \multirow{2}{*}{ Family Assistance } & Yes & $31(33.70)$ & $61(66.30)$ & $92(93.87)$ & \multirow{2}{*}{0.49} \\
\hline & No & $2(33.33)$ & $4(66.67)$ & $6(6.13)$ & \\
\hline \multirow{2}{*}{ School Enrolment } & Yes & 20 (35.09) & 37 (64.91) & $57(58.16)$ & \multirow{2}{*}{0.72} \\
\hline & No & $13(31.71)$ & $28(68.29)$ & $41(41.84)$ & \\
\hline \multirow{2}{*}{$\begin{array}{l}\text { Stroke } \\
\text { History }\end{array}$} & Yes & $6(42.86)$ & $8(57.14)$ & $14(14.29)$ & \multirow{2}{*}{0.61} \\
\hline & No & $27(32.14)$ & $57(67.86)$ & $84(85.71)$ & \\
\hline \multirow{2}{*}{$\begin{array}{l}\text { Diabetes } \\
\text { History }\end{array}$} & Yes & $4(22.22)$ & $14(77.78)$ & $18(18.37)$ & \multirow{2}{*}{0.39} \\
\hline & No & $29(36.25)$ & $51(63.75)$ & $80(81.63)$ & \\
\hline \multirow{2}{*}{$\begin{array}{c}\text { History of } \\
\text { Hypertension }\end{array}$} & Yes & $19(27.94)$ & $49(72.06)$ & $68(69.39)$ & \multirow{2}{*}{0.07} \\
\hline & No & $14(46.67)$ & $16(53.33)$ & $30(30.61)$ & \\
\hline \multirow{2}{*}{$\begin{array}{c}\text { History of Psychiatric } \\
\text { Disorders }\end{array}$} & Yes & $5(55.56)$ & $4(44.44)$ & $9(9.18)$ & \multirow{2}{*}{0.27} \\
\hline & No & $28(31.46)$ & $61(68.54)$ & $89(90.82)$ & \\
\hline
\end{tabular}




\begin{tabular}{cccccc} 
Continued & \multicolumn{1}{c}{} & & \\
\hline \multirow{2}{*}{ Aphasia } & Yes & $24(42.86)$ & $32(57.14)$ & $56(57.14)$ & 0.02 \\
& No & $9(21.43)$ & $33(78.57)$ & $42(42.86)$ & \\
Stroke Type & Haemorrhagic & $7(31.82)$ & $15(68.18)$ & $22(22.45)$ & \multirow{2}{*}{0.83} \\
Stroke & Ischemic & $26(34.21)$ & $50(65.79)$ & $76(77.55)$ & \\
Territory & Left & $22(66.67)$ & $25(38.46)$ & $47(47.96)$ & 0.008 \\
& Right & $11(33.33)$ & $40(61.54)$ & $51(52.04)$ & \\
Rankin Modified & Autonomous & $8(21.62)$ & $29(78.38)$ & $37(37.76)$ & 0.004 \\
& Invalid & $25(40.98)$ & $36(59.02)$ & $61(62.24)$ & \\
Rehabilitation & Yes & $31(32.61)$ & $62(67.39)$ & $93(94.90)$ & 0.99 \\
& No & $2(40.00)$ & $3(60.00)$ & $5(5.10)$ & \\
$\begin{array}{c}\text { Anti HTA } \\
\text { Treatment }\end{array}$ & Yes & $21(28.77)$ & $52(71.23)$ & $73(74.49)$ & \multirow{2}{*}{0.07} \\
\hline
\end{tabular}

\section{Discussion}

In our study, the frequency of the post-stroke depression was $33.67 \%$. This is close to the $38 \%$ reported in the literature [6]. Although some variation has been reported by region and study, this can range from $18 \%$ to $60 \%$ depending on the studies [7] [8] [9], however, two studies in Germany reported a higher frequency of $72.3 \%$ [10] [11]. These large differences can be explained by the variability of the methods used, higher reported frequency of depression in the European countries could also explain the difference [12].

According to our results, the post-stroke depression was more frequent in subjects aged 50 to 70 years, male and married, please note that, life expectancy in the general population in Senegal is $64.8 \%$ [1]. Data found in literature also points in the same direction for age [9] [13] [14] [15], marital status [16] [17] and gender [9] [18] [19]. It's also important to notice that in our study, the prevalence of post-stroke depression is higher among active patients (39.2\%) compared to non-active subjects (27.66\%), this is however not of statistical significance. Stroke in this context translates into a loss of physical autonomy and financial resources for both the subject and his or her family. Often, the one who has hitherto been providing for the family often becomes a family financial burden. In a context of limited economic resources associated with a lack of medical coverage; it is easy to understand that the occurrence of stroke can impact the quality of marital, family and even social relationships [20]. Therefore, very often, among these active subjects, there is also the question of returning to the premorbid job or professional reorientation in relation to the deficit caused by stroke. In the same way, the medical history of the patient seems to be important to consider. Patients with a medical history of diabetes (22.2\%) or hypertension (27.9\%) have a lower incidence of Post-stroke depression compare to these without the same history. The chronic nature of these conditions, combined with the work of raising awareness of possible complications, may lead to greater 
patient compliance and in the event of a stroke, lesser complication and better resilience. This experience may be quite the opposite in subjects with no such long-standing history of diabetes and/or hypertension. In contrast, according to some authors [21] [22], a history of stroke (before the actual incident) may be strongly associated with the onset of a Post-stroke depression. The same applies to a history of psychiatric disorders, particularly depression. These are a risk factor for the development of Post-stroke depression [5] [23] [24] [25]. In our study, the prevalence of depression was $55.6 \%$ among individuals with history of psychiatric disorder and $31.5 \%$ among individuals who did not have.

From a clinical point of view, stroke is determined by three major factors: the deficit caused the type of stroke and its location. In this study, aphasia was the most frequently encountered symptom (57.1\%); we found statistically significant high post-stroke depression (42.9\%) among aphasic subjects compared to $21.4 \%$ non-aphasic subjects $(\mathrm{p}<0.05)$. This finding is similar to those reported in European countries [3] [21]. Language disorders correlate with the loss of the symbolic ability [26], impacting the relationship with the others and particularly among couples [27].

Several studies have shown the link between functional disability and the occurrence of Post-stroke depression [2] [28] [29] [30]. We also observed this relationship in our study where depression was $75.8 \%(\mathrm{p}=0.04)$ more frequent among patients who were unable to walk alone and/or support themselves. According to Carota et al. [31], the intensity of depressive symptoms strongly correlates with the degree of functional disability. Thus, the presence of motor, perceptual or cognitive disability leads to devastating effects on sense of autonomy. Therefore, the resulting feelings of frustration could be a major aetiological factor in depression after a stroke.

In this study, the type of stroke does not appear to affect the occurrence of Post-stroke depression. The prevalence of Post-stroke depression was slightly higher in patients with ischemic stroke (34.2\%) than in patients with haemorrhagic stroke $(31.8 \%)$ without statistically significant difference. This is similar to the findings in larger proportions reported by Seetlani [9].

We found that patients with right cerebral hemisphere lesions were $52.1 \%$ of the population. However, Post-stroke depression was more common among those with a left hemispheric lesion $47.8 \%$ compared to right hemispherical lesions with $22 \%$, this difference is statistically significant with a $\mathrm{p}=0.08$. This finding is similar to those frequently reported in the literature [14] [31] [32] [33]. It is further supported by the valence hypothesis where she argues that, under physiological conditions, the left hemisphere is specialized in controlling positive emotions and the right hemisphere in controlling negative emotions. In case of dysfunction of the left hemisphere, there is a dominance of negative emotions of the right hemisphere, thus explaining the depressive symptoms. However, there are other authors who report association of post-stroke depression more with right hemispheric lesions [34] [35] and therefore, this debate is not yet settled. 
In treatment aspects Post-stroke depression was more frequent among subjects who did not receive functional rehabilitation (40\%) as compared to those who received functional rehabilitation (32.6\%), however, this difference is not statistically significant ( $\mathrm{p}=0.99$ ). According to some authors, the beneficial effect of rehabilitation on motor skills and therefore independence can have an impact against post-stroke depression [2] [36]. However, it is important to consider the irregularity of rehabilitation sessions in the Senegalese context, which is doubly justified by the lack of physiotherapists and the high cost of sessions by Senegal standard, between 4000 and 10,000 francs (\$8 to \$20). According to Capron et al. [37], depression can be seen as a deficit phenomenon with a decrease in psychomotor functioning and a disinvestment in rehabilitation work. On the other hand, it can also be seen as an active phenomenon. The principle of cognitive-motor interference considers depression as a cognitive task in its own right, which can be responsible for a monopolization of attention and executive resources through fixed ideas and depressive ruminations, competing with rehabilitation work in a dual-task model.

There are few studies on the evolution of the post-stroke depression [8], though generally the its' occurrence should be considered a poor prognostic factor. Studies have shown that post-stroke depression increases mortality by 3.5 folds among stroke patients compared to those without depression [38]. In addition, post-stroke depression increases the length of recovery time and the burden of sequelae, as such quality of life remains significantly reduced as caregivers are also over burdened [39].

In our study, we found that the progression during treatment is marked by a clear regression in depressive symptomatology with a decrease in the MADRS score in most patients at 3 months and 6 months, we found that $18 \%$ of the patients progressed well both psychologically and functionally. This highlights the need for psychological support for all patients and antidepressant treatment if necessary for some. From this perspective, selective serotonin reuptake inhibitors (SSRIs) have been shown to fewer side effects [22] [40] [41].

The majority of our study population benefited from family support, we, however, found that the frequency of depression was slightly higher among patients who did not receive family support. Though we are tempted to opine that family support should be seen as a factor of resilience, we cannot categorical make this conclusion due to the limitation of this study.

Educational level does not seem to have an impact on the occurrence of depression, but it could play a fundamental role in the follow-up of post-stroke patients. Indeed, our study population had $40.8 \%$ out-of-school subjects, which is in line with the national prevalence of $45.4 \%$ [1].

\section{Conclusion}

Stroke is longer uncommon in Africa and constitutes a public health problem whose prognosis is clouded by the occurrence of post-stroke depression. Post-stroke 
depression has long been under-diagnosed; it is now necessary to pay more attention to the mental state of patients with stroke. Without drawing hasty conclusions, we think that the existence of certain clinical elements should make fear of the occurrence of post-stroke depression. Among these, we can note the right location of the stroke, aphasia and a loss of autonomy. Early diagnosis of post-stroke depression associated with holistic care may improve patients' quality of life.

\section{Conflicts of Interest}

The authors declare no conflicts of interest regarding the publication of this paper.

\section{References}

[1] Mboup, M.C., Sarr, S.A., Dia, K., et al. (2015) Aspects étiologiques des accidents vasculaires cérébraux ischémiques au Sénégal. Pan African Medical Journal, 22, 201. https://doi.org/10.11604/pamj.2015.22.201.6078

[2] Diagne, N.S., Camara, M., Cisse, O., et al. (2016) Vécu post AVC d'une cohorte sénégalaise: quels facteurs de risque pour quel item de qualité de vie. Journal de réadaptationmédicale, 36, 156-160. https://doi.org/10.1016/j.jrm.2016.07.001

[3] Kauhanen, M., Korpelainen, J.T., Hiltunen, P., et al. (1999) Poststroke Depression Correlates with Cognitive Impairment and Neurological Deficits. Stroke, 30, 1875-1880. https://doi.org/10.1161/01.STR.30.9.1875

[4] Paolucci, S. (2008) Epidemiology and Treatment of Post-Stroke Depression. Neuropsychiatric Disease and Treatment, 4, 145-154. https://doi.org/10.2147/NDT.S2017

[5] Berney, A. and Guex, P. (2000) Dépression et autres troubles psychiatriques dans l'accident vasculaire cérébral. Revue Médicale Suisse, 4, 2300.

[6] Goossens, D. and Wiart, L. (2005) Dépression et accidents vasculaires cérébraux. EMC-Neurologie, 2, 157-162. https://doi.org/10.1016/j.emcn.2004.09.003

[7] Carota, A., Dieguez, S. and Bogousslavsky, J. (2005) Psychopathologie des accidents vasculaires cérébraux. Psychologie et Neuropsychiatrie du Vieillissement, 3, 235-249.

[8] Mpembikosi, M., Mampunza, M.A., Miezi, S., Massamba Kubuta, V., et al. (2014) Evolution clinique de la dépression post-accident vasculaire cérébral à Kinshasa. Revue Neurologique, 170, 614-620. https://doi.org/10.1016/j.neurol.2014.03.002

[9] Seetlani, N.K., Ali, A., Haroon, H., et al. (2015) Frequency of Depression in Patients with Stroke. Medical Channel, 21, 22-26.

[10] Lewin-Richter, A., Volz, M., Jöbges, M., et al. (2015) Predictivity of Early Depressive Symptoms for Post Stroke Depression. The Journal of Nutrition Health and Aging, 19, 754-758. https://doi.org/10.1007/s12603-015-0540-x

[11] Baumann, M. and Aïach, P. (2009) L' aidant principal face à l'AVC d'un proche. Medecine, 5, 184-188.

[12] Hackett, M.L., Yapa, C., Parag, V., et al. (2005) Frequency of Depression after Stroke A Systematic Review of Observational Studies. Stroke, 36, 1330-1340. https://doi.org/10.1161/01.STR.0000165928.19135.35

[13] Eriksson, M., Asplund, K., Glader, E.L., et al. (2004) Self-Reported Depression and Use of Antidepressants after Stroke: A National Survey. Stroke, 35, 936-941. 
https://doi.org/10.1161/01.STR.0000121643.86762.9a

[14] Napon, C., Kabore, A. and Kabore, J. (2012) La dépression post-accident vasculaire cérébral au Burkina Faso. Pan African Medical Journal, 13, 3.

[15] Qamar, Z.K. (2012) Depression among Patients and Relation with Demographic and Stroke Characteristics. Mémoire de Doctorat en Santé publique, 7, 21-24.

[16] Lima, A.C.S., Monte, A.S., Moura, E.R.F., et al. (2016) Depression Post-Stroke: Clinical Characteristics Associated. International Archives of Medicine Section: Psychiatry \& Mental Health, 9, No. 55.

[17] Ajiboye, P.O., Abiodun, O.A., Tunde-Ayinmode, M.F., et al. (2013) Psychiatric Morbidity in Stroke Patients Attending a Neurology Clinic in Nigeria. African Health Sciences, 13, 624-631. https://doi.org/10.4314/ahs.v13i3.15

[18] Simon, O. (2007) Dépression après accident vasculaire cérébral. Mini revue sang thrombose vaisseaux, 19, 248-254.

[19] Lyrer, P.A. (2000) Epidémie de l'accident vasculaire cérébral. Bulletin des médecinssuisses, 81, 2082-2085. https://doi.org/10.4414/bms.2000.07606

[20] Scheltens, P., Erkinjunti, T., Leys, D., et al. (1998) White Matter Changes on CT and MRI: An Overview of Visual Rating Scales. European Task Force on Age-Related White Matter Change. European Neurology, 39, 80-89. https://doi.org/10.1159/000007921

[21] Johnson, J.L., Minarik, P.A., Nyström, K.V., et al. (2006) Poststroke Depression Incidence and Risk Factors: An Integrative Literature Review. Journal of Neuroscience Nursing, 38, 316-327. https://doi.org/10.1097/01376517-200609000-00008

[22] Magloire, M.N. (2011) Manifestations neuropsychiatriques des accidents vasculaires cérébraux à Kinshasa. Mémoire en Médecine Neuropsychiatrie.

[23] Zuber, M. (2012) Dépression et accidents vasculaires cérébraux, Troubles dépressifs dans les pathologies neurologiques. 2nd partie.

[24] Ouimet, M.A., Primeau, F. and Cole, M.G. (2001) Psychosocial Risk Factors in Post Stroke Depression: A Systematic Review. Canadian Journal of Psychiatry, 46, 819-828. https://doi.org/10.1177/070674370104600905

[25] Najih, A. (2013) Dépression après accident vasculaire cérébral: évaluation de quatre vingt dix patients suivis pour AVCI. Mémoire de doctorat en psychiatrie. Maroc, numero, 45.

[26] Wurtz, B., Rambert, P.M., Gentils, R., et al. (2019) Aphasie: Reconnaître et soigner les différents types d'aphasie. Orthophenie. ooreka. https://orthophonie.ooreka.fr/comprendre/aphasie

[27] Aïach, P. (2007) L'aphasie, principal facteur aggravant du vécu d'un AVC par les proches. Médecine, 3, 130-135.

[28] Fernandez, L., Finkelstein-Rossi, J., Binet, S., et al. (2011) Accident vasculaire cérébral, dépression post accident vasculaire cérébral et stratégies de coping chez un sujet âgé: Apport du test de l'arbre. In: Finkelstein-Rossi, J. and Fernandez, L., Eds., Techniques Projectives: 12 cas cliniques, Concept Psy, Paris, 221-240.

[29] Duong, P.H. (2001) Comment diagnostiquer et traiter la dépression en soins palliatifs? Revue internationale de soinspalliatifs, 4, 10-16. https://doi.org/10.3917/inka.014.0010

[30] Wiart, L., Petit, H., Debelleix, X., et al. (1996) La dépression post AVC: Une entité à part entière. Annales de Réadaptation et de Médecine Physique, 39, 338. https://doi.org/10.1016/0168-6054(96)86884-X

[31] Carota, A. (2002) Dépression après accident vasculaire cérébral et localisation de la 
lésion. Schweizer Archiv für Neurologie und Psychiatrie, 159, 386-392.

https://doi.org/10.4414/sanp.2002.01317

[32] Frenisy, M.C., Minot, D., Soutenet, M., et al. (2005) Accidents vasculaires cérébraux: approche psychopathologique et approche neuropsychologique. A propos d'un cas: M.J. Annales Médico Psychologiques, 163, 65-72. https://doi.org/10.1016/j.amp.2004.11.009

[33] Camus, V. and Schmitt, L. (2000) Manifestations psychiatriques des affections cérébrovasculaires: Approche clinique et thérapeutique. Encyclopedie Médico Chirurgicale (Editions Scientifiques et Médicales Elsevier SAS, Paris, tous droits réservés), Psychiatrie, 37-545-A-14, 5 p.

[34] Oladji, J.O., et al. (2009) Risk Factors of Post Stroke Depression among Stoke Survivors in Lagos, Nigeria. African Journal of Psychiatry, 12, 47-51.

https://doi.org/10.4314/ajpsy.v12i1.30278

[35] Paolucci, S., Antonucci, G., Pratesi, L., et al. (1999) Poststroke Depression and Its Role in Rehabilitation of Inpatients. Archives of Physical Medicine and Rehabilitation, 80, 985-990. https://doi.org/10.1016/S0003-9993(99)90048-5

[36] Layadi, K., Belabed, A., Lahouel, F., et al. (2008) Evaluation de la dépression chez les hémiplégiques vasculaires. Journal de réadaptation médicale, 28, 93-96. https://doi.org/10.1016/j.jmr.2008.07.014

[37] Capron, J. (2015) Retentissement psychiatrique de l'AVC. NPG Neurologie-Psychiatrie-Gériatrie, 15, 353-358. https://doi.org/10.1016/j.npg.2015.04.003

[38] OMS (2011) Rapport sur la situation mondiale des maladies non transmissibles 2010.

[39] Hadidi, N., Treat-Jacobson, D.J. and Lindquist, R. (2009) Postroke Depression and Functional Outcome: A Critical Review of Literature. Heart Lung, 38, 151-162. https://doi.org/10.1016/j.hrtlng.2008.05.002

[40] Pariel-Madjlessi, S., Pouillon, M., Robcis, I., et al. (2008) La dépression: Une complication méconnue de l'accident vasculaire cérébral chez les sujets âgés. Psychologie \& neuropsychiatrie du vieillissement, 6, 3167-3176.

[41] Chollet, F., Tardy, J., Albucher, J.F., et al. (2011) Fluoxetine for Motor Recovery after Acute Ischaemic Stroke (FLAME): A Randomized Placebo-Controlled Trial. The Lancet Neurology, 10, 123-130. https://doi.org/10.1016/S1474-4422(10)70314-8 